\title{
Scientometric Mapping of Social Science Studies in East Asia and the Philippines
}

\author{
Paula Antoinette G. Acuña, Alfonso Carlo J. Ellasos, Jethro A. Bautista, Madhavi \\ Devaraj
School of Information Technology, Mapúa University, Manila, Philippines paulaagacuna@gmail.com,ace.ellasos@gmail.com, jethrobautista25@gmail.com,mdevaraj@mapua.edu.ph, madhavidevaraj@gmail.com

\begin{abstract}
This paper presents a scientometric analysis of research efforts done in the field of Social Sciences (SS) in the region of East Asia and the Philippines during the last 18 years for comparison. With the records indexed in Scopus, we performed a computational analysis of textual data and bibliometric for publications originating in East Asia and the Philippines. The analysis performed measures and produces results in find out the total SS research output of the East Asian Region and the Philippines, global share and rank, impact and growth trends, collaboration levels within the East Asian Region and a textbased keyword research topic trend. The analytical results provide insightful mapping of SS research work in the East Asian Region as well as the Philippines. After processing, the results showed that East Asian countries place most of their efforts on Economics, Sociology, and Political Science. The results also discovered that Social Science research experienced consistent growth in over 18 years. Especially, in the period of 2006-2011 where both East Asian countries and the Philippines experienced great growth in social science research. It has also been identified that older papers are more favored due to a bigger citation window than more recent papers. It has also been found that there has been a steady decrease of cited papers in the East Asian Region and The Philippines within the 18-year scope. The results found find connections with other economic and demographic indicators in East Asian countries as well as the Philippines. The analytic results presently made inferences of this paper will be useful in gauging the performance of professionals within academic institutions within the East Asian region and the Philippines and may provide opportunities for research and improve collaboration within the said countries in the Social Science field of study. Using what we had found, we'd like to broaden our scope to include the ASEAN region or other Asian Regions.
\end{abstract}

Keywords: Scientometrics, Citation analysis, social science research, research impact, research collaboration, East Asia, Philippines

\section{Introduction}

Scientometrics is the field in science that concerns itself with science, technology, and innovation in terms of its analysis and measurement. Most of its research efforts is placed on the measurement of influences made by scientific articles, the investigation of the impact that institutes and journals produce, the study of scientific citations, mapping scientific fields and the production of policy and management context indicators. [1] This field of science is important because it crosses over significantly with the many other fields of science such as Information Science and Bibliometric. Social Sciences is the field of science that concerns itself with the study of human society and the relationships

*Coordinate author - for correspondence (e-mail: mdevaraj@ mapua.edu.ph ; madhavidevaraj@gmail.com) 
that it entails. It is a field that is divided into different branches such as economics, political science, human geography, demography, psychology, sociology, anthropology, archaeology, jurisprudence, history, and linguistics, all of which are considered a "social science". [2] What makes social science important with concerns to the other sciences is ability to provide insight into how science and innovation work - in effect it is the science of science. Social scientists contain important communication and analytical capabilities for dealing with the many industries and organizations. [3]

This research focuses in combination of the field of Scientometrics to the field of Social Sciences. Scientometrics as a topic of research is relatively new when it comes to the context of the Philippines since there has yet to be a Scientometric paper produced by the country. If not, at least none for the field of Social Science. This claim is backed by a query placed in the Scopus Database in the subject of Scientometrics with Philippines as an affiliated country, which yielded no result. As Social Science is the study of human society, this research chose East Asia as its scope because the country with the largest population in the world, China belongs in this group of countries. But not only China, Japan is also a part of East Asia and lands the rank of being the 10th most populated country in the world while South Korea, also an East Asian country lands the rank of $26^{\text {th }}$. As the research's scope has a part for largely populated countries, it adds more reason to using the context of the Philippines because it is also a densely populated country ranking at $12^{\text {th }}$ largest in the world [4]. The research attempts to measure and map the top 3 social sciences used as a research subject in the East Asian reason in comparison with the Philippines during the past 18 years from the years 2000-2017 to be able to gain an understanding the status and scenario of the Social Sciences in this region. This research concentrates its efforts with the scientometric bibliographic data taken from Scopus Database. This research focuses in gaining results in important indicators in Social Science research in East Asia as well as the Philippines. These indicators include total research output, global share, growth and impact, citation count and patterns, and trend analysis. This also includes a scientometric analysis for a limited time period per country in East Asia and the Philippines. The research additionally included insightful secondary indicators such as the collaboration behavior within East Asia and an Index Keywordbased analysis of research topic trends. The analysis route includes East Asia and the Philippines in the last 18 years. There are existing recent related literature works that have performed scientometric analysis on specific countries or specific regions $[7,9,10,11]$ or domain for a time period and/or country [8]. We have based this research on a scientometric research by Ussin and Singh [5] where demographic and economic correlations on research outputs are determined. From these literatures, especially the paper of Uddin and Singh, we derived and adopted their methodologies in order to create this research. A book on scientometrics by De Bellis was also used to aide in this research [12].

\section{Data Collection}

We began the collection of data for scientometric analysis by amassing raw bibliographic data from Scopus, the largest abstract and citation database for peer-related literature. This data collection method was seen to be the commonly used approach in data collection from reviewed literatures. Another common data collection method is by using the research outputs indexed from Web of Science $[15,16,18,20]$. Other data collection methods are as follow: Science Citation Index [6,17], Proceedings of the National Academy of Sciences [13], DBLP for Computer Science [14], and Web of Knowledge [19]. The data set comprises of papers related to social science studies, published in East Asian countries ${ }^{1}$ and in Philippines during the year 2000-2017. The data set limit it to papers such as Articles, Reviews, Conference Papers, and Editorials, and are

\footnotetext{
${ }^{1}$ China, Japan, Mongolia, South Korea, North Korea, and Taiwan
} 
published in English language only. When limited to the subject area of Social Sciences in the language of English, Scopus yields over 2,163,457 document results. When the query parameters is increased to only include East Asian countries, Scopus yields over 173,868 results. If the Philippines is included in the query, it becomes 176, 939 results. The document records was exported and had undergone manual cleaning by 3 people to avoid errors and remove unnecessary papers not included in the scope. Manual cleaning was first initiated to the records of China to find the top 3 branches of social science used as a research subject of the country which were Economics, Sociology and Political Science. The limit to the said top 3 branches found was added to the current query to narrow the results down the results to 4,588 document papers. After another manual cleaning to remove duplicates and papers marked as retracted, the resulted dataset was 4,373.

\section{Research and Global Share}

The total number of research output and the global shares of East Asia and the Philippines was the first parameter this research attempted to measure and analyze. This measurement was done in two ways: First, total research output of the world in the last 18 years and then total research output by East Asia and the Philippines split into chronological blocks of 6 years each. While the first measurement tells the total efforts of East Asia and the Philippines in the research of Social Sciences during the concerned period, it also shows how much of it constituted the research output of the entire world in the same field of study. The block measurement was done this way to allow an idea about the growth trend of research output in the last 25 years. Table 1 shows a detailed statistic of the total research output in Social Science by the top 10 research-producing-countries, East Asia, and the Philippines. This also includes mappings for population and economic indicators for the included countries in the table. China appears at the top 2nd position of this list. Japan appears at the 12th and South Korea at the 17th. The Philippines follows on later at the 53rd position in terms of total research output. As the table had shown, East Asia is home to some of the countries that are very active in the studies of Social Sciences. Specifically, China as it is how to the largest population in a country on the plant. The Philippines and Japan is similar in that aspect as despite them being a small country, have a large population as well.

In Table 2, the research presents the total research output in the East Asian Region. The second column of this table (Total Paper (TP) in East Asia) shows all research papers produced by the region regardless of discipline. The Third column (TP in East Asia on SS) shows all research papers in the domain of Social Sciences only. It could be seen that recent efforts in Social Science research take up 1.28\% (2000-2005), 3.14\% (2006-2011), and 2.80\% (2012-2017) of the total research output of the East Asian region, regardless of discipline in the last 18 years. It could also be seen that there has been a clear trend of interest and growth over Social Sciences as a research subject over the 6-year chronological blocks. Despite it being rated as $1.28 \%, 3.14 \%$, and $2.8 \%$ in the effort of total output in the region, when compared to the total research output of the world entire world in the last 6 years, East Asian Social Science research makes up 3.50\% (20002005), 9.20\% (2006-2011), and 9.17\% (2012-2017) of the total research output of the world. In Social Science research, East Asia has been holding itself over 9\% (East Asia's contribution to the total research output of the entire world was 9.20\% from 2006-2011). On the other hand, Social Science research makes up 10.90\% (2000-2005), 14.37\% (2006-2011), and 15.82\% (2012-2017) of the Philippines' total research output in the recent 6 years and makes up $0.10 \%, 0.12 \%$, and $0.18 \%$ for the three consecutive year blocks respectively of the world's total research output as shown in Table 3. 


\begin{tabular}{|c|c|c|c|c|c|c|}
\hline no. & Country & $\begin{array}{l}\text { No. of } \\
\text { publications }\end{array}$ & $\begin{array}{l}\text { Population } \\
\text { (2017) }^{2} \\
\text { (million) }\end{array}$ & $\begin{array}{l}\text { GDP (PPP) } \\
(2017)^{4} \text { US\$ } \\
\text { (billion) }\end{array}$ & $\begin{array}{l}\text { Publication } \\
\text { per capita }\end{array}$ & $\begin{array}{l}\text { Publication } \\
\text { per GDP }\end{array}$ \\
\hline 1 & United States & 750,269 & 325.15 & $19,417.14$ & 2307.46 & 38.64 \\
\hline 2 & United Kingdom & 259,726 & 64.77 & $2,905.39$ & 4009.97 & 89.39 \\
\hline 3 & Australia & 106,746 & 23.23 & $1,251.42$ & 4595.18 & 85.30 \\
\hline 4 & Canada & 102,526 & 35.62 & $1,752.91$ & 2878.33 & 58.49 \\
\hline 5 & China & 93,271 & 1379.3 & $23,194.41$ & 67.62 & 4.02 \\
\hline 6 & Germany & 74,814 & 80.59 & $4,134.67$ & 928.33 & 18.09 \\
\hline 7 & Netherlands & 56,543 & 17.08 & 907.62 & 3310.48 & 62.30 \\
\hline 8 & Spain & 47,217 & 48.96 & $1,768.82$ & 964.40 & 26.69 \\
\hline 9 & Italy & 42,849 & 62.14 & $2,303.11$ & 689.56 & 18.60 \\
\hline 10 & France & 41,595 & 67.11 & $2,833.06$ & 619.80 & 14.68 \\
\hline 12 & Japan & 33,351 & 126.45 & $5,420.23$ & 263.75 & 6.15 \\
\hline 15 & Taiwan & 24,585 & 23.51 & $1,177.05$ & 1045.73 & 20.89 \\
\hline 17 & South Korea & 23,688 & 51.18 & $2,029.71$ & 462.84 & 11.67 \\
\hline 53 & Philippines & 3,087 & 104.26 & 878.98 & 29.61 & 3.51 \\
\hline 123 & Mongolia & 218 & 3.07 & 37.731 & 71.01 & 5.78 \\
\hline
\end{tabular}

\section{Growth Trend and Impact}

Our second parameter was to measure the growth rate and impact of Social Science research output of East Asian countries and the Philippines of the last 18 years. The data is mapped to 3 blocks of 6 years each to show a clearer output. Tables 2 and 3 displays the total quantifiable value for research outputs in the East Asian region and the Philippines respectively. The rate of growth was calculated using the data for the current block and the preceding block. From the data seen in Table 2, the last two blocks for East Asia's research growth rates are 402\% (2006-2011 compared to 2000-2005) and 20\% (2012-2017 compared to 2006-2011). This clearly shows that the total research output for Social Science of countries in the East Asian region has greatly increased in the past 18 years. For the Philippines, there has also been an increase with research growth rate in the Social Science field of 135\% (2006-2011 compared to 2000-2005) and 90\% (2012-2017 compared to 2006-2011). Similarly to East Asia, the Philippines saw a great increase during the 2006-2011 year block.

\section{Table 2. Total Research Output (All Subjects and Social Science Alone) in East Asia and the World ${ }^{5}$}

\begin{tabular}{|c|c|c|c|c|c|}
\hline Period & TP in EA & $\begin{array}{c}\text { TP in EA } \\
\text { on SS }\end{array}$ & $\begin{array}{c}\text { SS as \% of } \\
\text { TP in EA }\end{array}$ & TP in SS in world & $\begin{array}{l}\text { research output of } \\
\text { world }\end{array}$ \\
\hline 2000-2005 & $1,137,997$ & 14,533 & 1.28 & 414,942 & 3.50 \\
\hline 2006-2011 & $2,324,133$ & 73,022 & 3.14 & 794,125 & 9.20 \\
\hline 2012-2017 & $3,127,369$ & 87,558 & 2.80 & 954,408 & 9.17 \\
\hline
\end{tabular}

\footnotetext{
${ }^{2}$ https://www.census.gov

${ }^{3}$ GDP (PPP): Gross Domestic Product (at Purchasing Power Parity)

${ }^{4}$ https://www.imf.org/

${ }^{5}$ TP: Total papers; EA: East Asia; SS: Social Science
} 


\section{Table 3. Total Research Output (All Subjects and Social Science Alone) in the Philippines and the World ${ }^{6}$}

\begin{tabular}{lccccc} 
Period & TP in Ph & $\begin{array}{c}\text { TP in Ph } \\
\text { on SS }\end{array}$ & $\begin{array}{c}\text { SS as \% of } \\
\text { TP in Ph }\end{array}$ & TP in SS in world & $\begin{array}{c}\text { Ph's \% share of SS } \\
\text { research output of } \\
\text { world }\end{array}$ \\
\hline $\mathbf{2 0 0 0 - 2 0 0 5}$ & 3,625 & 395 & 10.90 & 414,942 & 0.10 \\
$\mathbf{2 0 0 6 - 2 0 1 1}$ & 6,451 & 927 & 14.37 & 794,125 & 0.12 \\
$\mathbf{2 0 1 2 - 2 0 1 7}$ & 11,159 & 1,765 & 15.82 & 954,408 & 0.18
\end{tabular}

Aside from the quantifiable value of the research output, it is also imperative to measure the impact of these outputs. A good method to measure this could be the citation data. Viewing the citation count of a research output is an effective measure of the usefulness and influence of a research. Block-wise data was used to measure the citation impact of Social Science research output of the East Asian region and the Philippines and computed the average citations per paper for all 6 blocks or a 3-year increment. Figures 1 and 2 shows the plot of the average citations per paper for East Asia and the Philippines, respectively. However, using the average citation per paper [ACCP] alone are in favor of older papers as there has been a greater citation window for these and there are more papers from recent years thus giving a result with smaller values. So as to get a better visualization of the citation impact, the time window is needed to be taken into account. Thus, time-adjusted average citation per paper was also found.

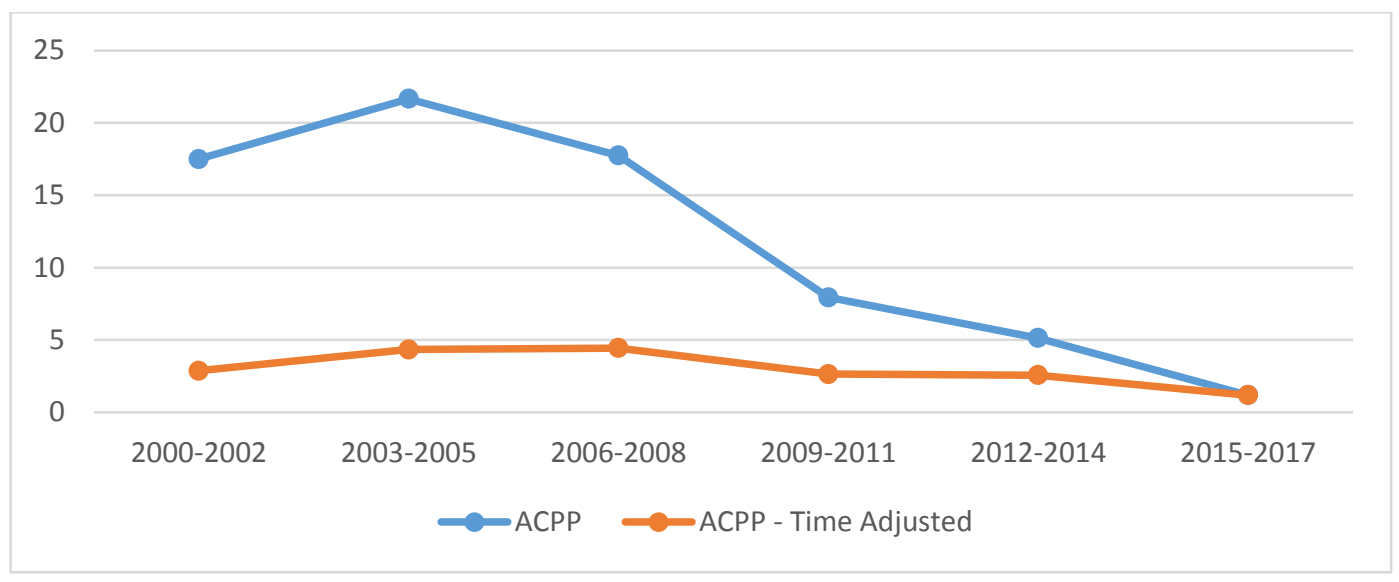

Figure 1. Average Citation per Paper in East Asia with Time

${ }^{6}$ TP: Total papers; Ph: Philippines; SS: Social Science 


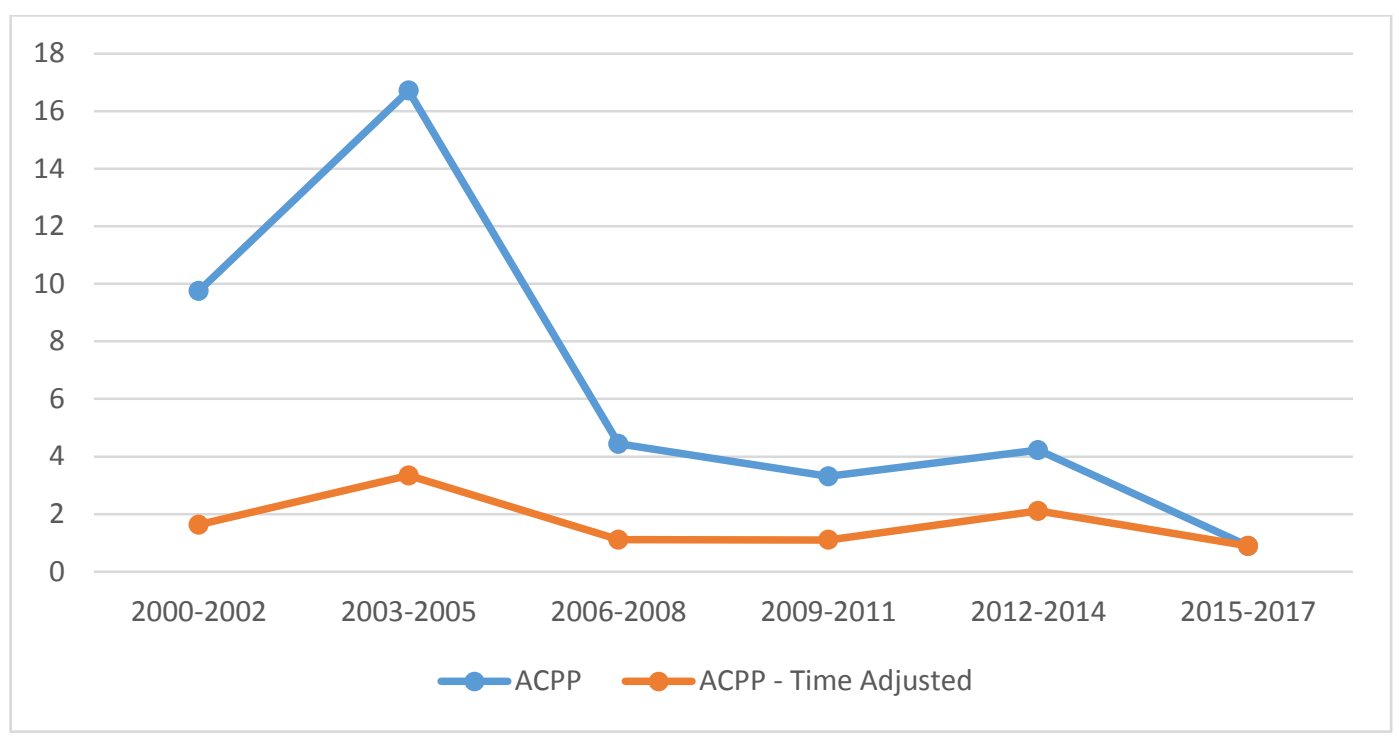

Figure 2. Average Citation per Paper in the Philippines with Time

Further, the growth of research in the Philippines and East Asian countries were identified. This could give an indication of the growth of research in the Philippines as compared to East Asian countries. Figure 3 shows a year wise statistics of citations from the countries within the East Asian region and the Philippines during the span of 18 years. It is observable that China is leading in the number of citations especially from 2008 onwards. Compared to the rest of East Asia, the Philippines has a lower citation count except when compared to Mongolia. This could be due to the fact that Philippines and Mongolia have less overall research outputs compared to the rest of East Asia in the past 18 years as shown in table 1 and that these two countries have the lowest GDP.

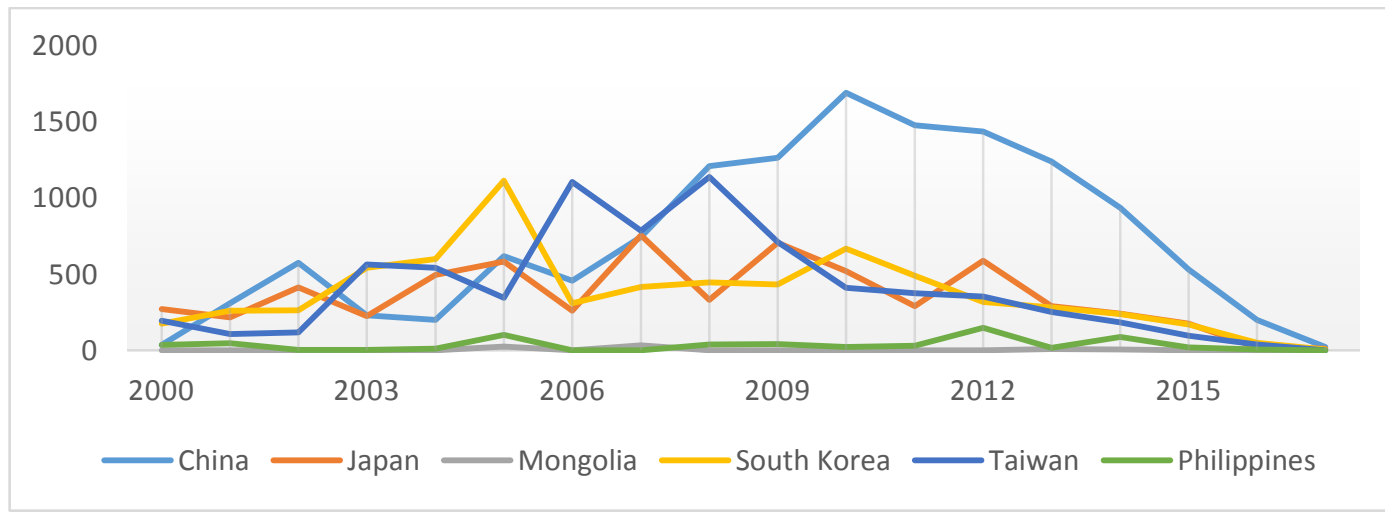

Figure 3. Citation Patterns of Social Science Research in East Asia vs the Philippines

\section{Cited vs Uncited Research Papers}

A research output is seen as impactful and useful if it garners interests from other researchers therefore a citation-based analysis could be a good measure of productive and useful research. In order to do this, the proportion of research outputs generated by East Asian countries and the Philippines that are cited or uncited was measured. Three blocks of 6 years is used to present the proportion of cited vs. uncited papers from 2000-2017. As seen in figure 4, it can be observed that for East Asia the proportion of cited papers decreases. The reason for this seems to be the smaller time window for citation and the 
large amount of research output. This seems to be a similar case to the Philippines as seen in figure 5.

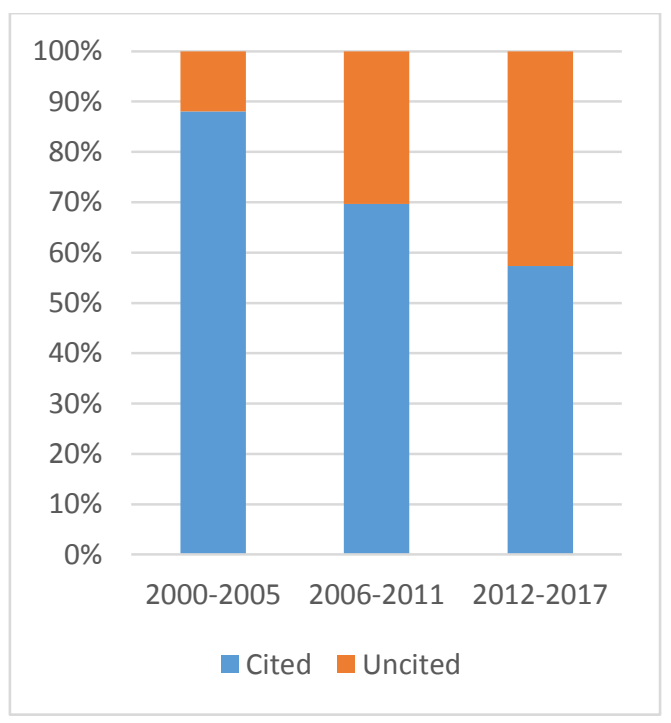

Figure 4. Cited vs. uncited Social Science Research in East Asia during Three Blocks

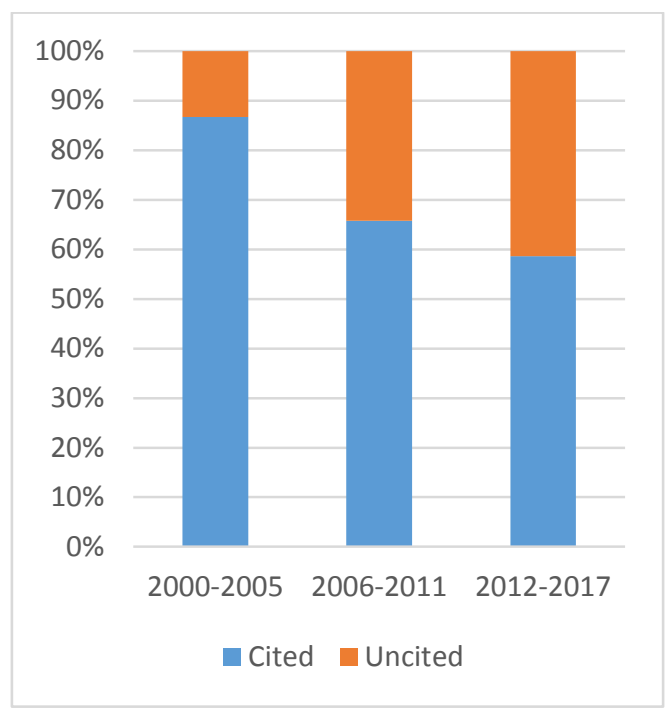

\section{Figure 5. Cited vs. Uncited Social Science Research in the Philippines during Three Blocks}

\section{Keyword-based Research Trend Analysis}

There are many areas of research in Social Science and it is an ever growing area. It is, therefore, useful to have an idea on the trend changes in time. In order to visualize this, the "indexed keywords" field in the dataset was extracted from all the values. The values are then mapped over three 6-year blocks. The results from all the countries are merged to create a list of keywords to identify the frequency of occurrences. This list is then used to generate a word cloud to emphasize the most frequently used keywords. In figure 6 (a), (b), (c), we can observe that from our dataset "economic(s)" is the dominating keyword for each block. However, we can see that "health" is a more prominent topic from 2000- 
2005, "power" for the 2006-2011 block, and from 2012-2017 there are more variations of topics.

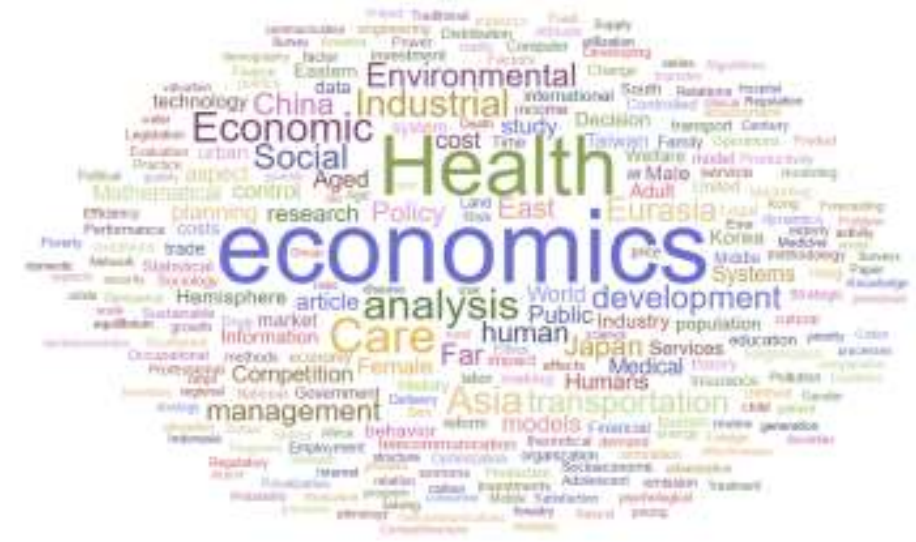

Figure 6 (a). Index Keyword Tag Clouds for Years 2000-2005

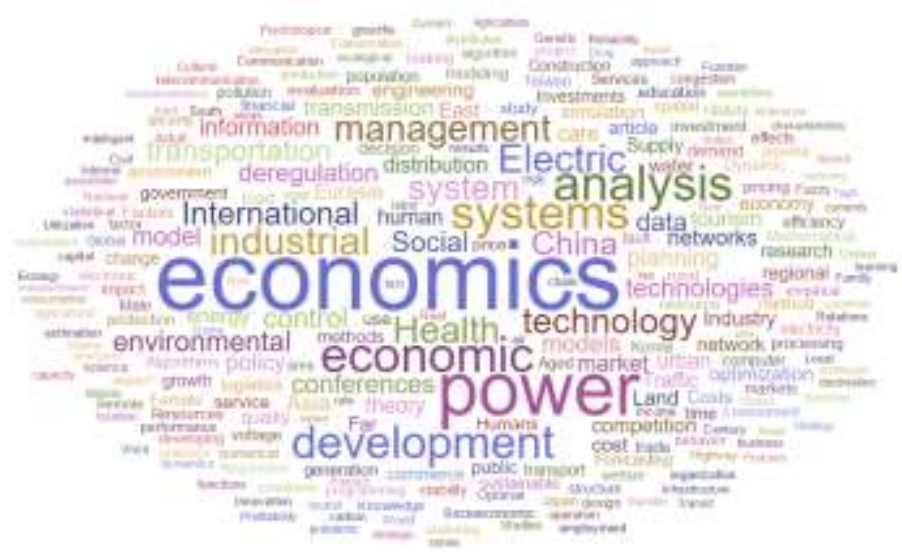

Figure 6 (b). Index Keyword Tag Clouds for Years 2006-2011

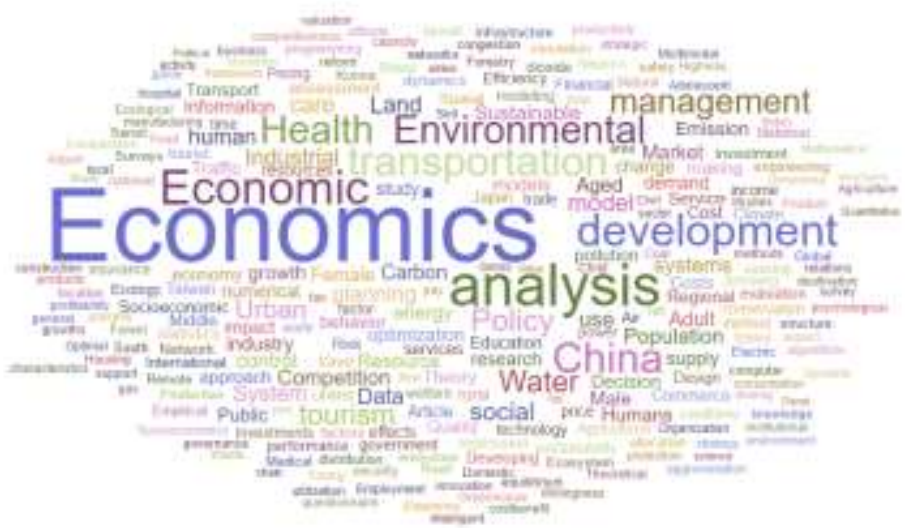

Figure 6 (c). Index Keyword Tag Clouds for Years 2012-2017

\section{Conclusion}

This paper presents scientometric analysis of social science research in East Asia and Philippines. Important factors such as total research output, global share, growth trends and impact, citation proportion, and research trends were identified to measure the 
research output of the Philippines in the Social Science domain and compared their result with the outputs from the East Asian region. Identification of citation counts and patterns, in this research enabled to measure the impact and productivity of research from these specified nations.

The results from this research may be used in order to evaluate the performance of processionals in institutions in East Asia and the Philippines, among other things. This may also help in the improvement of collaboration levels. It is important to not stay within the boundaries of your own nation when producing a research, collaboration with other nations or societal norms can be beneficial in creating a more useful and universal output. The Social Science domain is a substantial area of research and has a worldwide effect, there is a definite need for this. It is essential for future growth that there would be an improvement with the research outputs and disciplines in this domain.

\section{References}

[1] L. Leydesdorff and S. Milojević, International Encyclopedia of Social and Behavioral Sciences, $7^{\text {th }}$ ed. Amsterdam: Elseview, 2015.

[2] "Social science", Wikipedia, 2017. [Online]. Available: https://en.wikipedia.org/wiki/Social_science. [Accessed: 22-May-2017].

[3] Study International Staff, "The Importance of the Social Sciences", Study International, 2017. [Online]. Available: https://www.studyinternational.com/news/the-importance-of-the-socialsciences/\#RMBoTYQ4OyyCT342.97. [Accessed: 22-May-2017].

[4] “Population Clock: World”, Census, 2017. [Online]. Available: https://www.census.gov/popclock/world. [Accessed: 03-Jun-2017].

[5] A. Uddin and V. Singh, "Mapping the Computer Science Research in SAARC Countries", IETE Technical Review, vol. 31, no.4, pp. 287-296, 2014.

[6] A. Basu and V. Kumar, "International collaboration in Indian Scientific Papers", Scientometrics, vol. 48, no. 3, pp. 381-402, 2000.

[7] Rupika, A. Uddin and V. Singh, "Measuring the University-Industry-Government Collaboration in Indian Research Output", Current Science, vol. 110, no. 10, p. 1904, 2016.

[8] L. Heilig and S. Vob, "A Scientometric Analysis of Cloud Computing Literature", IEEE Transactions on Cloud Computing, vol. 2, no. 3, pp. 266-278, 2014.

[9] M. Singh and N. Hasan, "Trend in research output and collaboration pattern among BRICS countries: A scientometric study", 2015 4th International Symposium on Emerging Trends and Technologies in Libraries and Information Services, 2015.

[10] S. Banshal, A. Uddin, K. Singhal and V. Singh, "Computer science research in India: A scientometric study", 2015 Annual IEEE India Conference (INDICON), 2015.

[11] N. Shirakawa, T. Furukawa, K. Hayashi and M. Tamamura, "Double-loop bench marking methods in the era of data deluge: An empirical scientometric study and assessment of Japan's Galapagos syndrome in scientific research activities," Proceedings of PICMET '14 Conference: Portland International Center for Management of Engineering and Technology; Infrastructure and Service Integration, Kanazawa, 2014, pp. 2799-2806.

[12] N. De Bellis, Bibliometrics and citation analysis, 1st ed. Lanham, Md.: Scarecrow Press, 2009.

[13] K. Garimella and H. Xiao, "Media Attention to Science", 2017 International World Wide Web Conference Committee, 2017, pp. 779-780, 2017.

[14] S. Agarwal, N. Mittal, R. Katyal, A. Sureka, and D. Correa, "Women in Computer Science Research", ACM Computers \& Society, vol. 46, no. 1, pp. 7-19, 2013.

[15] A. Basu, S. Banshal, K. Singhal and V. Singh, "Designing a Composite Index for research performance evaluation at the national or regional level: ranking Central Universities in India", Scientometrics, vol. 107, no. 3, pp. 1171-1193, 2016.

[16] S. Banshal, V. Singh, A. Basu and P. Muhuri, "Research performance of Indian Institutes of Technology", Current Science, vol. 112, no. 5, pp. 923-932, 2017.

[17] A. Basu and R. Aggarwal, "Internation collaboration in science in India and its impact on institutional performance", Scientometrics, vol. 52, no. 3, pp. 379-394, 2001.

[18] A. Uddin, V. Singh, D. Pinto and I. Olmos, "Scientometric mapping of computer science research in Mexico", Scientometrics, vol. 105, no. 1, pp. 97-114, 2015.

[19] V. Singh, S. Banshal, K. Singhal and A. Uddin, "Scientometric mapping of research on 'Big Data', Scientometrics, vol. 105, no. 2, pp. 727-741, 2015.

[20] A. Uddin, S. Bhoosreddy, M. Tiwari and V. Singh, "A Sciento-text framework to characterization of the Leading World Institutions in Computer Science Research", 15th International Society of Scientometrics and Informetrics Conference, Instanbul, 2015, pp. 1267-1268. 


\section{Authors}
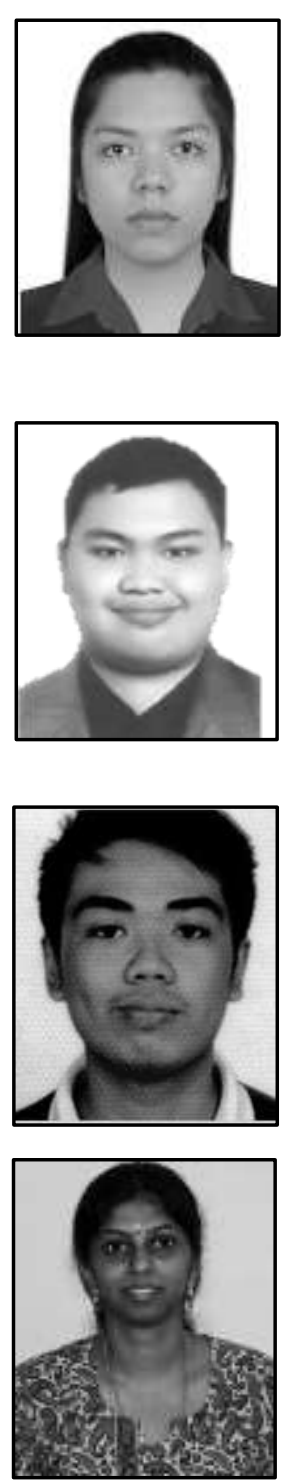

Paula Antoinette G. Acuña is currently an undergraduate student for Bachelor of Science in Computer Science - Mapúa University, Manila, Philippines. Her research interest is in scientometric, text analytics, machine learning, and artificial intelligence.

E-mail: paulaagacuna@gmail.com

Alfonso Carlo J. Ellasos is currently an undergraduate student for Bachelor of Science in Computer Science - Mapúa University, Manila Philippines. His research interests include software development, data processing, text analytics, and scientometric.

E-mail: ace.ellasos@gmail.com

Jethro A. Bautista is currently an undergraduate student for Bachelor of Science in Computer Science - Mapúa University, Manila, Philippines. His research interests are scientometric, text analytics, and network management.

Email: jethrobautista25@gmail.com

Madhavi Devaraj received MCA and MPhil degrees in computer science from Madurai Kamaraj University, Madurai, India, and doctoral degree in computer science from Dr. A.P.J Abdul Kalam Technical University, Lucknow, India. She has been assistant professor in computer science department at Invertis University and Babu Banarasi Das University previously. Currently, she is professor in computer science department at Mapúa University, Manila, Philippines. Her research interests include text analytics and scientometric.

Email:mdevaraj@mapua.edu.ph,madhavidevaraj@gmail.com 